\title{
HOW DOES HISTOPATHOLOGY CORRELATE WITH CLINICAL AND OPERATIVE FINDINGS IN ABDOMINAL HYSTERECTOMY?
}

\author{
Khan $\mathrm{R}^{1}$, Sultana $\mathrm{H}^{2}$
}

\begin{abstract}
Many a times the clinical and per operative diagnosis does not correlate with histopathological diagnosis. Aim of this study was to compare the clinical, peroperative and histopathological findings of different cases of fibroid uterus, dysfunctional uterine bleeding and chronic cervicitis which needed abdominal hysterectomy. In this prospective study 100 cases of abdominal hysterectomy were done over a period of two years. Among them $\mathbf{3 8 \%}$ cases were of leiomyoma uterus and $20 \%, 18 \%, 12 \%, 7 \%$ and $5 \%$ were of dysfunctional uterine bleeding, chronic cervicitis, pelvic inflammatory disease, benign ovarian tumours and endometriosis (external and adenomyosis) respectively. Cases studied on the basis of history, clinical examination and per operative findings. Specimens were sent for histopathology and reports were analyzed. It was thus co-related with the clinical presentation and per operative findings. Among 100 cases, 38 cases were of myoma diagnosed clinically but histopathological findings of 8 patients were different (adenomyosis in 6 cases and normal finding in 2 cases). Among 20 cases of clinically diagnosed dysfunctional uterine bleeding, 6 cases were found to have myoma and adenomyosis on histopathological examination.
\end{abstract}

Key words: Histopathology findings, hysterectomy, diagnosis

\section{Introduction}

Abdominal hysterectomy means complete removal of uterus through abdominal route. Hysterectomy is the most commonly performed major operation in gynaecology $y^{1,2}$. The increase in the number of hysterectomies may be attributed to prophylaxis against uterine cancer, mild genital prolapse, premenopausal menorrhagia ${ }^{3}$. Hysterectomy, however, must never be done without proper indications. According to Dicker, Hysterectomy should be performed when the risk of preserving the uterus is greater than the risk of it's removal or when there are disabling symptoms for which there is no successful medical treatment ${ }^{4}$. Surgical mortality rate from hysterectomy is $0.1 \%-0.2 \%$ but morbidity continues to be a problem and sometimes serious post operative complication like urinary extravasations, haemorrhage (in $0.2 \%-2 \%$ of patients) may develop ${ }^{5}$. Morbidity like bladder injury in $2 \%$ cases, infection in $10 \%$ cases, troublesome vaginal granulations in $10 \%$ cases, may develop ${ }^{6,7}$. So, hysterectomy should not be done as prophylaxis against normal cervical cytology or to facilated hormone replacement therapy to avoid endometrial hyperplasia ${ }^{8}$. Even for menorrhagia removal of the uterus should not be performed as a first hand management without a trial of medical treatment. Uterus should never be preserved if radiotherapy given to induce radiation menopause because of the higher incidence of malignancy following radiotherapy. The improve hospital care, availability of blood transfusion, advanced anesthesia and above all the advent of antibiotics has opened up a new era and thereby broaden the indications for hysterectomy with minimum postoperative morbidity and mortality.

In Bangladesh hysterectomies are performed having more or less similar indications as those perform in advanced countries ${ }^{9}$. Because of the limited facilities and economical constraints, diagnosis of the cases are made more on the clinical grounds rather than on the modern investigations. Even in the clinical assessments, there are considerable problems as the patients are mostly illiterate and ignorant and they do not understand the gravity of their symptoms, often attain the doctor late and cannot explain their problems without leading questions. As a result the findings often does not co-relate with their complaints.

\section{Patients and Methods}

A prospective study was designed to correlate clinical diagnosis of indications of hysterectomy with subsequent histopathological report/diagnosis. The study was conducted at the department of Obstetrics and Gynaecology, Combined Military Hospital of Ghatail Cantonment during the period March 2007 to March 2009. The patients were diagnosed on the basis of history, clinical examination and Ultrasonography reports. 


\section{Inclusion criteria:}

Patients with age 35-60 years and with benign gynaecological conditions with failed medical treatments like -

- Uterine leiomyoma or fibroid with menorrhagia or with intermenstrual bleeding

- Dysfunctional uterine bleeding with no identifiable pathological cause, but unacceptable menstrual blood loss for the patient

- Pelvic inflammatory disease with pelvic pain and severe dysmenorrhoea

- Severe and intractable endometriosis

- Benign ovarian tumour

Exclusion criteria :

Following cases were excluded from the study -

- Patients with a diagnosis or history of cancer

- Patients who had an emergency hysterectomy for paripartum haemorrhage

- Patients who had a major conprocedure like thyroid, heart, breast, stomach, gall bladder, colon and kidney surgery

One hundred cases were available during that period. The clinical findings of all patients were co-related with per operative findings. Finally after operation, the specimens were sent for histopathological examination and reports were analyzed and the clinical diagnosis were co-related with per operative and histopathological findings in a tabulated form.

\section{Results}

Among 100 patients underwent hysterectomy, 38 presented with Leiomyoma uterus (Table-I).Most of the patients presented with menorrhagia; associated complaints like pain in lower abdomen or dysmenorrhoea and lump in lower abdomen.Cases of dysfunctional uterine bleeding, presented with irregular bleeding per vagina. In pelvic inflammatory disease most cases complained of dyspareunea and dysmenorrhoea. The chronic cervicitis mostly presented with excessive mucus discharge per vagina with dysmenorrhoea and

Table-I : Distribution of cases as per peroperative diagnosis.

\begin{tabular}{|l|c|c|}
\hline \multicolumn{1}{|c|}{ Clinical diagnosis } & Number & Percent \\
\hline Leiomyoma uterus & 38 & 38 \\
\hline $\begin{array}{l}\text { Dysfunctional uterine } \\
\text { bleeding }\end{array}$ & 20 & 20 \\
\hline $\begin{array}{l}\text { Pelvic inflammatory } \\
\text { disease }\end{array}$ & 12 & 12 \\
\hline Chronic cervicitis & 18 & 18 \\
\hline Benign ovarian tumour & 07 & 07 \\
\hline $\begin{array}{l}\text { Endometriosis (external } \\
\text { and adenomyosis) }\end{array}$ & 05 & 05 \\
\hline
\end{tabular}

Table-II: Complications following hysterectomy. $(\mathrm{n}=48)$

\begin{tabular}{|l|c|c|}
\hline Complications & Number & Percent \\
\hline Fever & 10 & 20.83 \\
\hline $\begin{array}{l}\text { Urinary tract } \\
\text { Infection }\end{array}$ & 08 & 16.67 \\
\hline $\begin{array}{l}\text { Abdominal wound } \\
\text { infection }\end{array}$ & 10 & 20.83 \\
\hline $\begin{array}{l}\text { Respiratory tract } \\
\text { infection }\end{array}$ & 05 & 10.42 \\
\hline $\begin{array}{l}\text { Pain in lower } \\
\text { abdomen }\end{array}$ & 08 & 16.67 \\
\hline Vault granuloma & 05 & 10.42 \\
\hline Loose motion & 02 & 4.17 \\
\hline
\end{tabular}

Table-III: Distribution of cases with different histopathological diagnosis $(n=23)$.

\begin{tabular}{|l|c|l|l|l|}
\hline $\begin{array}{l}\text { Clinical } \\
\text { diagnosis }\end{array}$ & Number & $\begin{array}{l}\text { Per-operative } \\
\text { diagnosis }\end{array}$ & Histopathological findings & Final diagnosis \\
\hline Fibroid uterus & 6 & Fibroid uterus & $\begin{array}{l}\text { Endometrium - secretory phase } \\
\text { Myometrium- Adenomyosis } \\
\text { Cervix- Chronic cervicitis }\end{array}$ & Adenomyosis \\
\hline Fibroid uterus & 2 & Fibroid uterus & $\begin{array}{l}\text { Endometrium - proliferative phase } \\
\text { Myometrium- unremarkable } \\
\text { Cervix- healthy }\end{array}$ & DUB \\
\hline Fibroid uterus & 7 & Fibroid uterus & $\begin{array}{l}\text { Endometrium- Secretory phase. } \\
\text { Myometrium- multiple small } \\
\text { myoma and adenomyosis } \\
\text { Cervix- healthy }\end{array}$ & Adenomyosis \\
\hline Fibroid uterus & 2 & Fibroid uterus & $\begin{array}{l}\text { Endometrium - Proliferative phase, single } \\
\text { endometrial polyp. } \\
\text { Myometrium- Adenomyosis Cervix- } \\
\text { Chronic Cervicitis }\end{array}$ & Edenomyosis and \\
\hline Eumetrial polyp.
\end{tabular}


some presented with chronic low backache and dyspareunea. Seven patients presented with benignovarian tumour and showed lump in lower abdomen. Five patients were diagnosed clinically as external endometriosis and two as adenomyosis. Most of their complaint was severe dysmenorrhoea total 48 patients developed various complications after hysterectomy that are shown in Table-II.

Ten patients needed 1-2 pints of blood per and postoperatively. Two patients required secondary suture, others wound infections were cured by changing antibiotics and regular dressing. Of the vault granuloma cases 1 patient needed electrocautery and others cured by chemical cautery.

Co-relation with Histopathology Report : Seventyseven cases were co-related clinically with histopathological diagnosis but 23 cases had a different diagnosis than the clinical one. Detail co-relation is shown in Table-III.

\section{Discussion}

Hysterectomy is one of the most common operations done in women with an expected lifetime prevalence of $10 \%{ }^{10}$. This study was performed to find the common indications, complication and morbidity of abdominal hysterectomy and to correlate the clinical presentation with the per-operative and histopathological findings. The diagnosis was mostly based on patients' symptoms and clinical findings. In all cases ultrasonographic help was taken but ultrasonic findings did not correlate in all cases. This study included some of the common indications of hysterectomy for example: Leiomyoma, Dysfunctional uterine bleeding, chronic cervicitis, pelvic inflammatory disease ${ }^{11}$. Among 100 cases, 38 cases were of myoma diagnosed clinically but histopathological findings of 8 patients were different (adenomyosis in 6 cases and normal finding in 2 cases). Incidence of leiomyoma is $20 \%$ in reproductive age group and increases with age $\mathrm{e}^{6}$. In this study incidence was more i.e. $38 \%$, probably due to clinical or pre-operative diagnosis was done prior to histopathological findings. Contrast hysterosalpingography (HSG) may be diagnostic in some cases of adenomyosis ${ }^{12}$, but the yield is too low to justify routine use. MRI is useful for the diagnosis of adenomyosis, but the cost of the procedure preclude it's routine use and the facility is not easily available in peripheral situation. Among 20 cases of dysfunctional uterine bleeding, 6 cases were myoma and adenomyosis on histopathological examination. Here also preoperative diagnostic error can be reduced, if help of HSG, laparoscopy and MRI could be available. Preoperative diagnosis, that were not confirmable, were diagnosed as uterine bleeding, pelvic pain including lower abdominal pain.
An attempt was made to compare the present study with some international studies. In Nancy C Lee's series, the major pathological findings were recorded for each case from each of the anatomic sites i.e. cervix, endometrium, myometrium, fallopian tubes and ovaries ${ }^{13}$. A hysterectomy specimen was considered to be normal if the cervix, endometrium, myometrium, fallopian tubes and ovaries were noted to be normal or if the specimen had no abnormality other than functional ovarian cysts. In Nancy C Lee's series, in over half of all the cases the fallopian tubes and ovaries were not removed. Same was practiced for the present study. Of those, whose uterus were removed most of the fallopian tubes were normal, while functional ovarian cysts were most common ovarian findings. In Nancy C Lee's series, leiomyoma of myometrium was found in $70 \%$ cases but in present series it was $55 \%$ cases. Also in case of two years study of Tariq Sarfraz and Humaira Tariq in 100 cases of hysterectomy it was $48 \%{ }^{14}$. The endometrium specimens were normal in $85 \%$ cases in Nancy C Lee's series, 91\% in Tariq and Humaira study and $93 \%$ of present series. Twenty two percent of hysterectomy specimens had no substantial abnormalities on the post-operative pathological examination in Nancy C Lee's series and in the present series it was $21 \%$. In present series, average hospitalization was for 9 days and postoperative stay was 7 days. According to Hassan Amirikia and TN Evans, in their study of 6,435 hysterectomies performed in Hutzel Hospital during a 10 years period, the duration of hospital stay was on average 10.5 days ${ }^{15}$. According to Hassan Amirikia, $76 \%$ of the hysterectomies were performed for Leiomyoma uterus but Steven $\mathrm{C}$ reports only $19.6 \%$ of incidence. In the present series, $38 \%$ of hysterectomies were done for leiomyoma uterus. Hysterectomies done for Dysfunctional uterine bleeding in the series of Richard C Dicker and Nancy C Lee's were $17.8 \%$ and $21 \% 13$ and in the present series it is $20 \%$ and in Tariq and Humaira study it is $8 \%{ }^{16}$. Hysterectomy done for Pelvic inflammatory disease showed wide variation from $72 \%$ in Richard C Dicker and $16 \%$ in Steven $\mathrm{C}$ White series. In present series it is $12 \%$. Death occurred in the percentage of $0.1 \%, 0.26 \%$ and $0.67 \%$ in different series studied by Richard $\mathrm{C}$ Dicker, Hassan Amirikia and Steven C White ${ }^{13,15}$. In the present study there was no death among 100 cases. Currently, the mortality rate associated with hysterectomy is less than $0.1 \%{ }^{17,18}$. In the present study of 100 cases of hysterectomy, patients were followed up for short period. About $70 \%$ were relieved from heavy bleeding, which was the most frequent benefit and most important benefit in $61 \%$ cases. Most of the women reported improvements in symptoms experienced before hysterectomy but one patient complained the persistence of symptoms or worsened after hysterectomy. 


\section{Conclusion}

This study confirms that benign pathologies are more common in hysterectomy specimens than their malignant counterparts and that the most common pathology identified in hysterectomy specimen is leiomyoma and then adenomyosis. The clinical and histopathological corelation is not $100 \%$ in cases of leiomyoma, dysfunctional uterine bleeding or pelvic inflammatory disease.

\section{Refernces}

1. Dicker CJ, Greenspan JR, Strauss LT, et al. Complications of abdominal and vaginal hysterectomy among women of reproductive age in United States. American Journal of Obstetrics and Gynaecology 1982;144:841-48

2. Lumsden MA, Twaddle S. A randomized comparison and economic evaluation of laparoscopic assisted and abdominal hysterectomy. British Journal of Obstetrics and Gynaecology 2000; 107:1386-91.9.

3. Olsson JH, Ellstrom M, Hahlin M. A randomized prospective trial comparing laparoscopic and abdominal hysterectomy. British Journal of Obstetrics and Gynaecology 1996; 103:345-50.

4. Dicker RC, Seally MJ, Greenspan JR, et al. Hysterectomy among women of reproductive age trends in United States. JAMA 1990; 248: 328-335.

5. Decherley AH, Nathan L. Current Obstetrics and Gynaecology diagnosis and treatment. 9th ed. USA: MC Graw-Hill; 1991. p.865-876. 6. Bhatia N. Jeffcoate's Principle of Gynaecology. 6th ed. London: Hodder Headline Group, 2001. p.466-482.

7. Ahsan S, Naeem S, Ahsan A. A case note analysis of hysterectomies performed for non-neoplastic indication. Liaquat National Hospital, Karachi. J Pak Med Ass 2001; 51(10):346-9.

8. Wood C, Maher P, Hill D, Selwood T. Hysterecttomy: a time of change, Med J Aust 1992;157:651-653.

9. Dutta DC. Textbook of Gynaecology. 2nd ed. Calcutta: New Central Book Agency Ltd; 2003. p.529-55.

10. Wicox LS, Koonin LM, Peterson HB, Pokras R, Strauss LT, Xia Z. Hysterectomy in the United States 1988-1990, Obstet Gyn 1994;83: 549-555.

11. Cameron IT. Laparoscopy and laparoscopic surgical techniques. In: Whitfield CR, ed. Drewhurst Textbook Obstetrics and Gynaecology for Postgraduate Students, 6th edn. London: Blackwell Scientific Publication; 1999. p.505-22.

12. Vora IM, Raizada RM, Rawal MY, Chadda JS. Adenomyosis. J Postgrad Med 2005; 27: 7-11.

13. Lee NC, Dicker RC, Robbin JL. Confirmation of the pre-operative diagnosis for hysterectomy. American Journal of Obstetrics \& Gynaecology 1998; 320: 421-427.

14. Sarfraz T, Tariq H. Histopathological findings in menorrhagia - a study of 100 Hysterectomy specimens. J Pak Pathol 2005 July-Sep; 16(13): 83-5.

15. Hassan A, Evan TN. 10 years review of hysterectomies trends, indications and risks. American Journal of Obstetrics and Gynaecology 1997; 134:431-437.

16. Shergill SK, Shergill HK, Gupta M, Kaur S. Clinicopathological study of hysterectomies. Indian Med Assoc 2002;10094:238-9.

17. Maresh MJA, Metcalfe MA, Pherson K, et al. The VALUE national hysterectomy study, description of the patient and their surgery. BJOG 2002; 109:302-312.

18. Weber AM, Lee JC. Use of alternative technique of hysterectomy in Ohio, 1988-1994. N Engl J Med 1996; 335:483-489. 